\title{
Genetic tagging shows increased frequency and longevity of antigen-presenting, skin-derived dendritic cells in vivo
}

Sanjay Garg, Alp Oran, Janine Wajchman, Shin Sasaki, Charles H Maris, Judith A Kapp \& Joshy Jacob Nature Immunology 4, 907-912

In the September 2003 issue of Nature Immunology, the bars on the graph in Figure 3b were misidentified in the legend. The first sentence of the legend to Figure $3 \mathrm{~b}$ should have read: "ROSA26 mice (five mice per group) were immunized by gene gun with DNA vaccines encoding Cre only (black bars), Cre and caspase 2 (open bars) or Cre and mutant caspase 2 (grey bars; apoptotic activity is 10\% that of wild-type caspase 2).” This mistake does not affect the message of the paper.

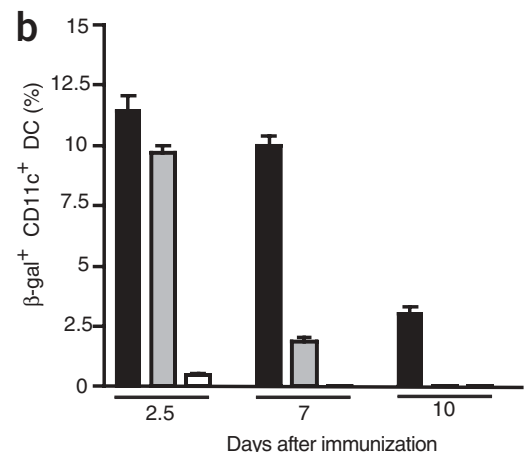

